\title{
Impact of Mediating Role of Employees' Creativity \& Relationship of Leadership Styles and Employees' Commitment to Change at Private Sector Universities in Sindh Province- Pakistan
}

\author{
Riyaz Hussain Massan ${ }^{1} \&$ Dr. Munwar Hussain Pahi ${ }^{2}$ \\ ${ }^{1}$ MBA MPhil, Indus University Karachi Sindh, Pakistan \\ ${ }^{2}$ Associate Professor, PAF Kiet University Karachi Sindh Pakistan \\ Correspondence: Riyaz Hussain Massan, MBA MPhil, Indus University Karachi Sindh, Pakistan. E-mail: \\ rizabro@hotmail.com
}

Received: August 19, 2019

Accepted: January 23, 2020

Online Published: January 31, 2020

doi:10.5430/bmr.v8n4p34

URL: https://doi.org/10.5430/bmr.v8n4p34

\begin{abstract}
Globally rapid progress of the organizations can be enumerated with their adaptability to change. Therefore, change must be coherent with leadership styles and be well coordinated with employees' willingness. It is comprehensible that organizations which did not familiarize and accept change could not survive and are no more in this business world. The target population of this study was permanent faculty members of the private universities in Sindh Province of Pakistan. Total 349 questionnaires were distributed to respondents of the Sindh province of Pakistan. Henceforth total 89 usable questionnaires were received from respondents. Data collected from permanent faculty members through questionnaires survey. To analyze the data, Partial Least Squares (PLS) path modeling was used by using Smart-PLS 2.0. The outcomes of this research work revealed a significant relationship between the transformational leadership and transactional leadership styles, furthermore transactional and transformational leadership styles mediate the relationship between employees' commitment to change and employee's creativity.
\end{abstract}

Keywords: transformational leadership style, transactional leadership style, employees' creativity, employees' commitment to change

\section{Introduction}

Change brings a big and a remarkable progress what organization anticipates for an outstanding wonder that employees and organizations see each day (Battilana, Gilmartin, Sengul, Pache, \& Alexander, 2010). Herold, Fedor, Caldwell and Liu (2008) and Martins (2008) showed that the probability of change has been observed and proved to be an outstanding conversion for the most critical difficulties seen in the organizations and for their pioneers to be vigilant at all levels. Furthermore, inside and outside influences such as: globalization, change or initiation of new businesses, economic viability and new innovation etc. compel organizations to react and make such innovations doable as their competitors carry for their betterment. Similarly, Herold et al. (2008) demonstrated that if the organization does not compete to day by day changes, it would not have the capacity to keep up its position in competitive age. Along with these lines, change is fundamental for the organizations to be legitimate and sincerely adopt it. The significance of hierarchical change explores has persistently been stressed by scholars and specialists, particularly the need, a superior comprehension of authoritative change from hierarchical and individual viewpoints. Employees' willingness for commitment to change is a remarkable feature for a fruitful change that can be upgraded by a viable leadership style and with a strong impact of employees' creativity. The present review was intended to analyze the relationship between leadership styles and employee's commitment to change and employees' creativity as an intervening variable. The review has some sort of suggestions for future practices, research and hypothesis. For practice, this examination may have direct and perpetual effect on the employees at private sector universities at Sindh province on the most proficient method to react to change execution. In a similar line, it can give pioneers a clear knowledge that how they can create an abnormal state of commitment for the change amongst the employees \& competitors, which exhibits the significance of employees' commitment to change. The review utilized transformational and transactional leaderships styles to decide employees' commitment to change. A quantitative approach was basically directed and determined for this review. With a specific end goal approach to accomplish the principle targets of this review, information will be 
gathered from employees of private sector universities at Sindh Province. Besides that, this exploration gives proof on the effect of employees' commitment to change, which can encourage the employees in the general population sector on the advancement of leadership. Building up a decent relationship among individuals in the organizations or be straightforward on the choice of change and further convey the normal commitment plainly to accomplish large amounts of commitment of change. Transformational pioneers enable employees to think innovatively, resolve their day to day issues from various points and investigate new and better answers for issues by utilizing innovation. In this review interceding part of employees' creativity between leadership styles and employees' commitment to change will be examined, thoroughly.

\section{Literature Review}

\subsection{Transformational Leadership}

Consumes (1978) brought up that transformational leadership can be seen as a way to raise an organization's requirement for change to a more elevated amount of inspiration and improvement. He additionally depicted transformational leaders as normal specialists, ready to enable subordinates to make a mission, culmination and gather objectives during the time spent in its execution. This style of leadership can improve employees' commitment to change. Bass $(1985,1990$ a) recognized that transformational leadership concentrates on the conduct of employee that may influence their conduct towards the organizations as it can change the fundamental qualities, convictions and states of mind of the subordinates. Consumes (1978) expressed that transformational leaders endeavor to bring subordinates, supporters, customers or electorates to a more noteworthy mindfulness about the issues of outcome. Thus, the point is to associate with employee's commitment to change by making devotees more mindful of the goals and expected commitments from them. What's more, Burns (1978) characterized a transformational leader as at least one people connected with others in any case that leaders and adherents increment the level of inspiration and ethical quality. This style of leadership dependably urges devotees to search for better approaches to their employment execution from persuasive inspiration to intellectual stimulation.

\section{H1: There is a significant relationship between transformational leadership style and employees' commitment to change.}

\subsection{Transactional Leadership}

As indicated by Burns (1978), this leadership guarantees that conduct is focused on an exchange procedure in which the leader gives prizes and disciplines as an end-result of the subordinate's endeavors and execution. It can be viewed as leaders who concentrate on achieving the objective and completing the undertaking; they ordinarily give careful consideration to the necessities of the organizations. (Avolio, 1999). In addition, Bryant (2003) expressed that transactional leaders have three primary qualities. Right off the bat, transactional leaders work with their gathering individuals and attempt to get a reward for their objectives. Furthermore, they exchange these prizes and guarantees of the reward for work exertion and for long lasting, they are responsive to the prompt self-interests of specialists. Transactional leadership exchanges what leaders expect and set up amongst objectives and prizes (Bryant, 2003). In addition, they include an exchange which is a basic component amongst leaders and devotees. Moreover, the leader relies upon the unforeseen prizes and on administration by special case. Accordingly, Bass (1985) proclaimed that this sort of leadership incorporates practices, for example, monitoring execution, giving unexpected individual rewards and giving unforeseen material rewards with the goal that assignments are done on time. Some doubtful issues that accomplished by powerful authoritative change that leaders require more than appeal; they should likewise show transactional practices, for instance illuminating objectives, setting up execution measures and applying prizes and disciplines (Nadler and Tushman, 1990).

H2: There is a significant relationship between transactional and transformational leadership styles and employees' commitment to change.

\subsection{Employees' Commitment to Change and Creativity}

Moreover, scholars have studied the correlation of employees' commitment to change and creativity. Jafri (2010) and eventually found that creative behavior is positively interconnected to an effective commitment to change and negatively correlated to continuance of commitment to change. Extending such understandings to creativity of the employees, we may expect that although organizational commitment to change is generally beneficial to creativity, afar from this opinion, it gradually adds up a less to an individual's commitment to generate creative solutions for the problems being faced in routine workability. Indeed, creativity by its virtue involves a growth of new ideas, but in applied and routine functioning it is not so much about idea generation, an open and unbound practical concerns but about the ideas that serve goal-oriented needs and organizational requirements. Accordingly, under the conditions of 
high commitment which has a relationship with creativity: the stronger commitment to change the higher creativity of employees. Furthermore, they endeavored to clarify how certain leaders could prompt large amounts of inspirations, trust and commitment among devotees. Thirdly, they focused on the typical or enthusiastic parts of the interest utilized by specific leaders and finally they determined the consequences for supporters, for example, expanded self-regard, inspiration and recognizable proof with the leader's vision. Bass (1985) created things depicting leaders' practices, subjected them to test and thought of three factors of transformational leadership which he later extended to four factors that described the practices, procedures and properties of the transformational leaders and their styles (Bass and Avolio, 1994).

H3: Employees' Creativity mediates the relationship between transactional leadership styles and transformational leadership styles and employees' commitment to change.

\subsection{Model}

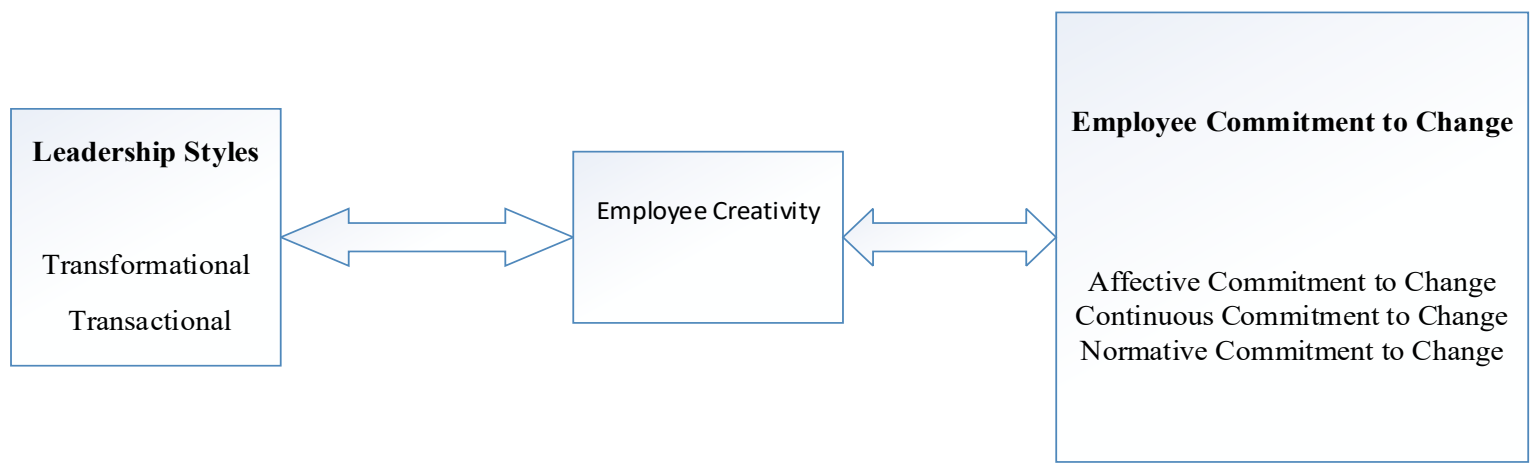

\section{Methodology}

Ghauri \& Grǿnhaug, (2005) proved that the type of research is totally based upon the research design of any study (either be quantitative, qualitative or mixed), it further depends upon the problem to be countered and answered. Therefore, all the approaches are dissimilar regarding the nature of the data. Qualitative research is purely depending upon the data which contains sentences, observations, words, photos and symbols. But on the other hand, quantitative research data comprises numbers and numeric (Cooper, Schindler, \& Sun, 2006). Whereas, mixed research methodology is founded on both the types, quantitative and qualitative approaches as defined by Creswell, Clark, Gutmann, \& Hanson (2003). In this study, the quantitative research methodology has been adopted, which is constructed on the justifications and also deliberated in the subsequent paragraphs. Quantitative research design is most appropriate methodology as confirmed the Cooper et al., (2006) and to further examine the relationship between the variables and for applying theories, models and hypotheses. And moreover quantitative research design is an appropriate to analyze the organizations between groups and dependency of rationalization among variables and it is the most suitable way of testing hypotheses. (Creswell et al., 2013) Therefore, survey methodology approach will be employed to meet the objectives of the study. It also includes the use of questionnaires as the main data collection technique for statistical analysis. Sampling process begins with the identification of the population, as illustrated by Sekaran (2009) who describes that, "population relates to the overall group of people or organization which might be the interest to the researcher". The population-target for this study is permanent faculty members of the private universities in Sindh province. The present study examined how leadership styles impact employee's commitment to change with mediating role of employee's creativity. In the current study, selection of permanent faculty members (lecturers) as the unit of analysis is most appropriate for a number of Population of this study are all the faculty members of private sector universities at Sindh Province. Participants include permanent faculty members (male and female).

\subsection{Data Analysis and Findings}

Survey was run by using convenience sampling. Numbers of questionnaire floated were 349 whereas 175 were returned which make it $50 \%$ return rate. However, while entering data rest of the questionnaires were rejected due to incomplete response by the respondent, therefore only 98 questionnaires were usable for data analysis.

\subsection{Measurement Model}

The measurement model was undertaken in this model evaluation as to ensure validity and reliability of the model. In line with arguments of Vinzi et al., (2010) the rule of thumb has been given for outer loading. Agreeing to their rule of 
thumb, outer loading should be up to 0.5 and above, as far as average variance extracted is concerned, it should be above 0.5 . Based upon the following argument all the items in outer loading which is below 0.5 should be deleted one by one with lowest value, (Hair et al., 2013; 14) because it improves the quality and reliability of the data and required result.

\subsection{Measurement Model (Figure 5.1)}

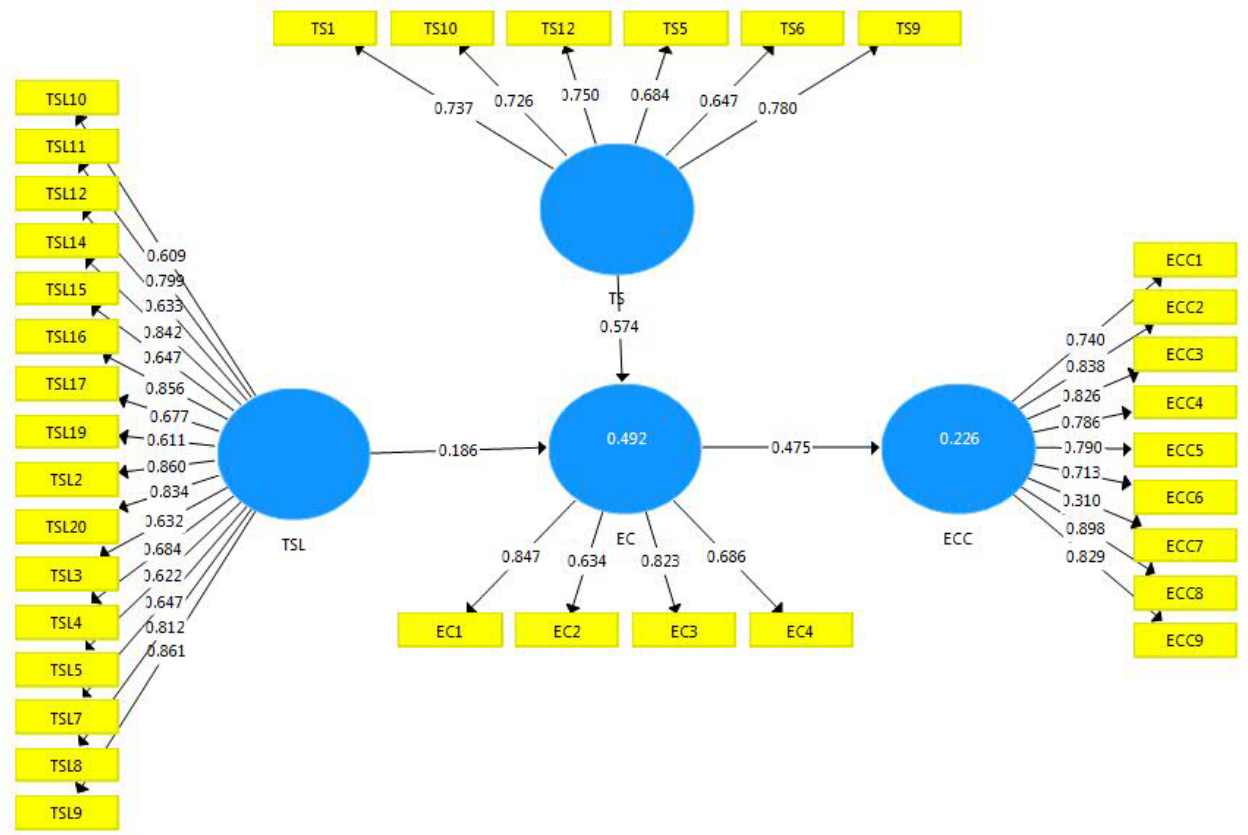

Table 1.

\begin{tabular}{llllll}
\hline Constructs & Items & Loadings & AVE & CR & R-square \\
\hline Employee's Creativity & & & 0.567 & 0.838 & 0.492 \\
& ECI & 0.847 & & & \\
& EC2 & 0.634 & & & \\
& EC3 & 0.823 & & & \\
& EC4 & 0.686 & & & \\
\hline EMPLOYEE'S COMMITMENT TO CHANGE & & & 0.586 & 0.924 & 0.226 \\
& ECC1 & 0.740 & & & \\
& ECC2 & 0.838 & & & \\
& ECC3 & 0.826 & & & \\
& ECC4 & 0.786 & & & \\
& ECC5 & 0.790 & & & \\
& ECC6 & 0.713 & & & \\
& ECC7 & 0.310 & & & \\
& ECC8 & 0.898 & & & \\
& ECC9 & 0.829 & & & \\
\hline
\end{tabular}




\begin{tabular}{|c|c|c|c|c|}
\hline \multirow[t]{7}{*}{ TRANSFORMATIONAL LEADERSHIP } & & & 0.521 & 0.867 \\
\hline & TS1 & 0.737 & & \\
\hline & TS2 & 0.726 & & \\
\hline & $\mathrm{TS} 3$ & 0.750 & & \\
\hline & TS4 & 0.684 & & \\
\hline & TS5 & 0.647 & & \\
\hline & TS6 & 0.780 & & \\
\hline \multirow[t]{17}{*}{ TRANSACTIONAL LEADERSHIP } & & & 0.538 & 0.948 \\
\hline & TSL1 & 0.609 & & \\
\hline & TSL2 & 0.799 & & \\
\hline & TSL3 & 0.633 & & \\
\hline & TSL4 & 0.842 & & \\
\hline & TSL5 & 0.647 & & \\
\hline & TSL6 & 0.856 & & \\
\hline & TSL7 & 0.677 & & \\
\hline & TSL8 & 0.611 & & \\
\hline & TSL9 & 0.860 & & \\
\hline & TSL10 & 0.834 & & \\
\hline & TSL11 & 0.632 & & \\
\hline & TSL12 & 0.684 & & \\
\hline & TSL13 & 0.622 & & \\
\hline & TSL14 & 0.647 & & \\
\hline & TSL15 & 0.812 & & \\
\hline & TSL16 & 0.861 & & \\
\hline
\end{tabular}

\subsection{Structural Model}

There are three structural models in this study, which are: direct relationship structural model, mediation structural model and structural model includes moderating variables. This segment deals with structural model after the evaluation of measurement model which is in direct relationships, (Hair et al., 2006) whereas, structural model deals with the dependency of the relationship in hypothesized model of the study. In PLS, structure model stretches inner modeling analysis of the direct relationship among the constructs of the study and their t-values, as far as path coefficients are concerned. Henseler et al. (2009), argued that the path coefficient is similar like the standardized beta coefficient as in the regression analysis. Whereas, beta values of the coefficient of the regression and t-values are scrutinized to further choose the significance. Following the rule of thumb as suggested by Hair et al., (2014), t-value greater than 1.64 is considered to be as significant, which is further used for making decisions on the purposed hypothesis. Firstly, the basic purpose of this study is to focus on model evaluation with examination of direct relationship, secondly test of the hypothesized relationships among the constructs through structural model. In this study three (03) hypothesis have been resulted which have direct relationships with employees' creativity and commitment to change were tested, all were proven to be supported. The Figure 4.1 displays the output results from the SmartPLS 2.0 M3 (Ringle et al., 2005) which shows the path coefficient values, $t$-values, $p$ - values as well as standard error. On the basis of these standard values, the hypothesis was supported or not by the researcher. The t-values in this study derived from bootstrapping (with 500 sampling iterations for 270 cases / observations. As argued by Hair et al. (2013), bootstrapping will serve as a proxy of parameters empirical standard error. According Hair et al. (2014), mediation test was done mainly to know whatever mediating variable enhance the impact of independent variable to the dependent variable. There are several techniques that have been used for mediation test such as baron and kenny (e.g. Baron \& Kenny, 1986), sobel test (e.g. Sobel, 1982) and bootstrapping (e.g. Preacher \& Hayes, 2004; Hayes, 
2009). So, as for current study point of view, re-sampling mediation technique (bootstrapping) was used by researcher to test the indirect effect of each potential variable. Likewise, majority of the researcher revealed that Bootstrapping a non-parametric re-sampling procedure was getting more attention for prospective researcher because this is one of the most rigorous and powerful procedure for testing the mediation effect (Hayes, 2009; Zhao et al., 2010). This bootstrapping for mediation analysis is said to be best suited for PLS-SEM because it can be applied to small sample size. In line with suggestion of Hair et al., (2014), when testing the mediation effects the researchers must follow (Preacher and Hayes 2004, 2008) bootstrap the sampling distribution of the indirect effects that works for simple and multiple models. This method is followed by determining the path coefficients by running PLS algorithm first of all, secondly running the bootstrapping as to get the t-values to determine if there is a direct relationship between the independent variables and dependent variable, before testing the mediation effect.

\section{Structural Model (Figure 6.1)}

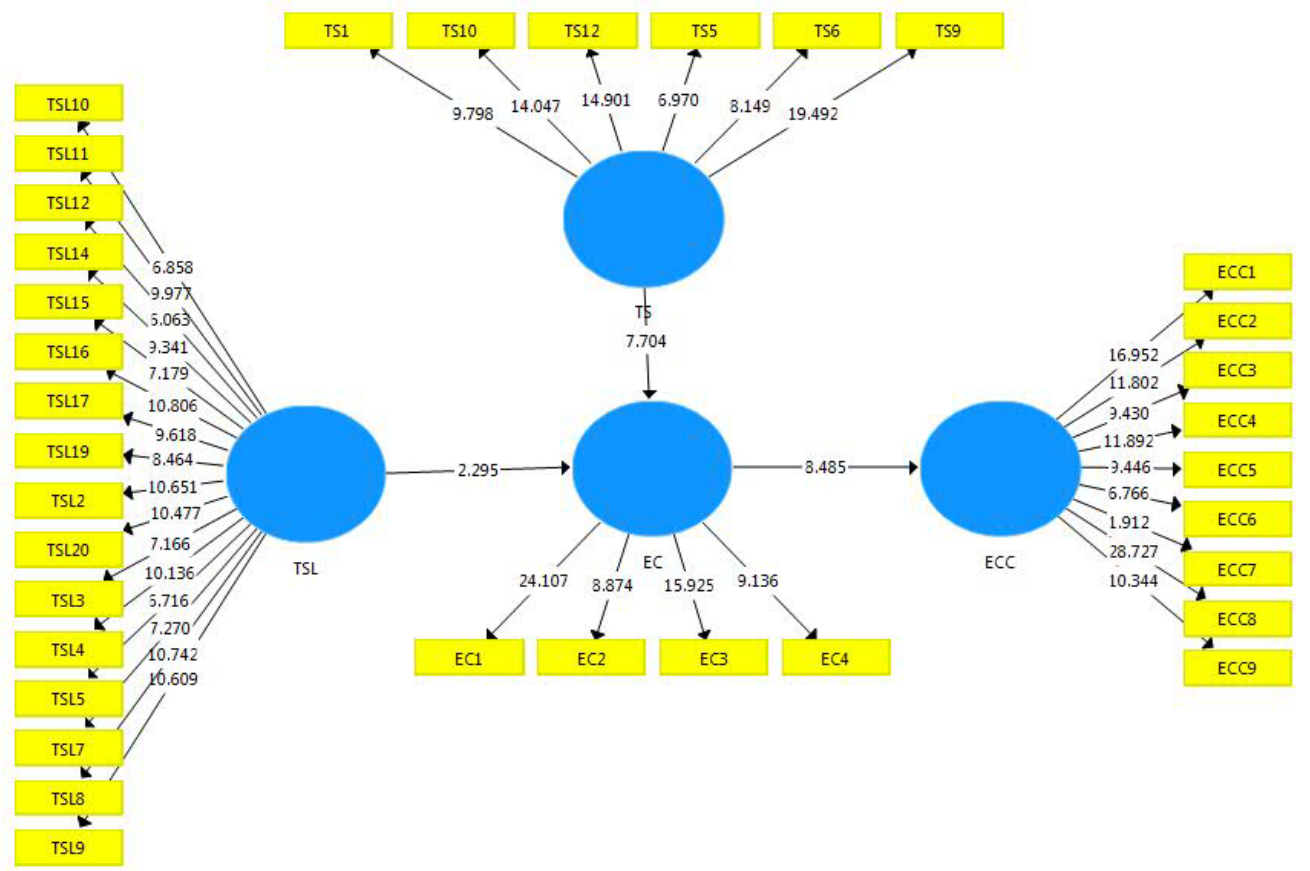

Table 1 shows that there is strong relationship between Transformational Leadership and Employee's Commitment to Change, mediator at $\mathrm{r}=.978$ (value of $\mathrm{p} \leqslant .01^{* *}$ ) and with Employee' $\mathrm{s}$ Creativity $\mathrm{r}=.816^{* *}$ (value of $\mathrm{p}$ ).

\section{Discussions}

This study pursued further to explore the process underlying the relationship of leadership styles and employee's commitment to change by considering the mediating role of employee's creativity. Particularly, this study was intended to empirically test the integrated model of the relationships and to broaden the understanding of literature in each field as well as to comprehend the influence of leaders over employees' commitment to change. However, results of the study are reflected and connected to related theories and further adding scientific understanding to leadership style, employees' commitment to change, and employee's creativity. Each hypothesis is discussed separately respecting to how the results put impacts over leaders, employees and moreover implications over the workplace. As per hypothesis, there is a significant relationship between transformational leadership style and employee's commitment to change. The results show that the transformational leadership style was positively related to employees; commitment to change. This is because transformational leadership style is one of the dominant leadership styles which affect employee's commitment to change has been extensively discussed within the extant leadership literatures. In this study, the empirical result indicates that transformational leadership is positive and significantly related to employee's commitment to change. Thus, the finding in this study is consistent with existing arguments in support of a positive relationship between transformational leadership and employee's commitment to change (Herold et al., 2008). 
It thus practically indicates that the faculty members of private sector universities at Sindh Province are responsive and more obedient to leaders who care about their individual and collective needs. It was found that transactional leadership had a positive significant relationship with employee's commitment to change. The findings, therefore, had confirmed the hypothesis. However, this finding in line with previous studies such as Lo et al., (2009) found that transactional have positive significant relationship toward the employee's commitment to change, the context of study where employees in private sector universities at Sindh Province City are more likely to have work in a tough way and therefore, favor the transactional management of doing work.

\section{Contributions of the Research}

This study has mainly contributed to the body of knowledge of the change management and leadership. The finding of this study has a significant contribution to the theory which comprises the field of the study, i.e. the commitment to change, leadership style, and employee's creativity; methodological contribution also has been discussed and finally, the practical contribution which included the managerial implication. This research has been contributed to the change management as general and in practical employee's commitment to change as well leadership style. The research was set to find clarity over earlier inconsistent finding of research in the same topic and further effort was taken by the current researcher to overcome the limitation highlighted by pervious researchers. Hence, the research finding has contributed to advance the body of knowledge concerning to the relationship between leadership style and employee's commitment to change. It has been affirmed by the researcher that, the area in which the researchers explored is empirically rare. Furthermore, it has been evidenced that leadership style was as the most important main factor of determinants the employee's commitment to change, which would contribute the theoretical foundation in the area of the change management. The findings of the relationship of the leadership styles and employee's commitment to change could add to the related literature, hence to compensate the weaknesses in such previous studies. In addition, the researcher focused on previous studies have empirically tested the mediating effect of employee's creativity on the relationship between leadership styles and employee's commitment to change. Hence, our findings emphasized that employee's creativity could play an important role towards the employee's commitment to change, which provides a significant contribution to the current literature on the change management. With a detailed review of the extant literatures and empirical findings, the current study has theoretically contributed to the body of knowledge on how individuals and organizational respond to the change. Importantly, it was developed a theoretical framework which has empirically assisted in establishing the relationships among leadership style, employee's creativity and employee's commitment to change. Similarly, each of the measures used in this study are relatively new within the research context. Finally, the present research contributes to the literature by investigating the issue of employee's commitment to change within the context of private sector universities of Sindh province.

\section{Methodological Contribution}

This study contributes to the methodological perspective in different ways. The quantitative method was used in this study in order to examine the relationship between the leadership styles and employee's creativity and employee's commitment to change. That would add value and significant contribution to the current finding on the change management phenomena. Moreover, the scales of the variables were adapted from previous research; they were applied in a different culture. We suggest that future research cross-validates our findings in different industries and cultures to verify their generalizability. Therefore, this provides a clear insight into change management in general and how leadership style affects employee's commitment to change as well as employee's creativity, in particular.

\section{Conclusion and Recommendations}

As the organizations struggles to develop, a pressure also develops which requires to understand the factors that may directly or indirectly affects people behaviors in organizations. However, this study was concerned with two important issues in the field of organizational change, leadership and employee's commitment to change as well as employee's creativity. The literature revealed that, both the subjects were considered as major contributors to the success of any change and alteration. In addition, the findings of this study showed that the transformational and transactional leadership styles were significant and positively related to the employee's commitment to change. Additionally, the findings exhibited that the employee's creativity was mediating the relationship between the leadership styles and employee's commitment to change. Thus, in terms of employee's commitment to change, these results provide support for the cross cultural applicability of Bass's augmentation theory of leadership, which claims that most successful leaders are both the transformational and the transactional. Equally important, the outcomes exposed that the employees' creativity play a significant role of mediating the relationship between the leadership styles and employees' commitment to change. Concluding the outcomes, we found that the employee's creativity was significant and positively changing the relationship between the leadership styles and employees' commitment to change, and it was 
revealed that once the employees' creativity increased the relationship was also increased. Therefore, the findings have confirmed the previous studies about the importance of employee's creativity for determinate and emphasized the relationship between the leadership style and employees' commitment to change. The results of this study were based on data collected from employees of private sector universities at Sindh Province. Future research is recommended to conduct similar studies in other organizational settings. Finally, future research is recommended to be focused on the other dimensions of the transformational and transactional leadership styles and employee's commitment to change results.

\section{References}

Avolio, B. J., Bass, B. M., \& Jung, D. I. (1999). Re-examining the components of transformational and transactional leadership using the Multifactor Leadership. Journal of occupational and organizational psychology, 72(4), 441-462. https://doi.org/10.1348/096317999166789

Baron, R. M., \& Kenny, D. A. (1986). The moderator-mediator variable distinction in social psychological research: Conceptual, strategic, and statistical considerations. Journal of personality and social psychology, 51(6), 1173. https://doi.org/10.1037/0022-3514.51.6.1173

Bass, B. M. (1985). Leadership and performance beyond expectations. Collier Macmillan.

Bass, B. M., \& Avolio, B. J. (1994). Shatter the glass ceiling: Women may make better managers. Human resource management, 33(4), 549-560. https://doi.org/10.1002/hrm.3930330405

Battilana, J., Gilmartin, M., Sengul, M., Pache, A. C., \& Alexander, J. A. (2010). Leadership competencies for implementing planned organizational change. The Leadership Quarterly, 21(3), 422-438. https://doi.org/10.1016/j.leaqua.2010.03.007

Carmichael, N. G., Barton, H. A., Boobis, A. R., Cooper, R. L., Dellarco, V. L., Doerrer, N. G., ... \& Pastoor, T. P. (2006). Agricultural chemical safety assessment: a multisector approach to the modernization of human safety requirements. Critical reviews in toxicology, 36(1), 1-7. https://doi.org/10.1080/10408440500534354

Cooper, D. R., Schindler, P. S., \& Sun, J. (2006). Business research methods (Vol. 9). New York: McGraw-Hill Irwin.

Creswell, J. W., Plano Clark, V. L., Gutmann, M. L., \& Hanson, W. E. (2003). Advanced mixed methods research designs. Handbook of mixed methods in social and behavioral research, 209, 240.

Deci, E. L., \& Ryan, R. M. (1987). The support of autonomy and the control of behavior. Journal of personality and social psychology, 53(6), 1024. https://doi.org/10.1037/0022-3514.53.6.1024

Druskat, V. U. (1994). Gender and leadership style: Transformational and transactional leadership in the Roman Catholic Church. The Leadership Quarterly, 5(2), 99-119. https://doi.org/10.1016/1048-9843(94)90023-X

Eisenberger, R., Huntington, R., Hutchison, S., \& Sowa, D. (1986). Perceived organizational support. Journal of Applied psychology, 71(3), 500. https://doi.org/10.1037/0021-9010.71.3.500

Eisenberger, R., Rhoades, L., \& Cameron, J. (1999). Does pay for performance increase or decrease perceived self-determination and intrinsic motivation?. Journal of personality and social psychology, 77(5), 1026. https://doi.org/10.1037/0022-3514.77.5.1026

Evanschitzky, H., Iyer, G. R., Plassmann, H., Niessing, J., \& Meffert, H. (2006). The relative strength of affective commitment in securing loyalty in service relationships. Journal of Business Research, 59(12), 1207-1213. https://doi.org/10.1016/j.jbusres.2006.08.005

F. Hair Jr, J., Sarstedt, M., Hopkins, L., \& G. Kuppelwieser, V. (2014). Partial least squares structural equation modeling (PLS-SEM) An emerging tool in business research. European Business Review, 26(2), 106-121. https://doi.org/10.1108/EBR-10-2013-0128

Fetters, M. D., Curry, L. A., \& Creswell, J. W. (2013). Achieving integration in mixed methods designs-principles and practices. Health services research, 48(6pt2), 2134-2156. https://doi.org/10.1111/1475-6773.12117

Hair, J. F., Ringle, C. M., \& Sarstedt, M. (2013). Partial least squares structural equation modeling: Rigorous applications, better results and higher acceptance. https://doi.org/10.1016/j.lrp.2013.01.001

Hayes, A. F. (2009). Beyond Baron and Kenny: Statistical mediation analysis in the new millennium. Communication monographs, 76(4), 408-420. https://doi.org/10.1080/03637750903310360 
Henseler, J., Ringle, C. M., \& Sinkovics, R. R. (2009). The use of partial least squares path modeling in international marketing. In New challenges to international marketing (pp. 277-319). Emerald Group Publishing Limited. https://doi.org/10.1108/S1474-7979(2009)0000020014

Herold, D. M., \& Fedor, D. B. (2008). Change the way you lead change: Leadership strategies that really work. Stanford University Press. https://doi.org/10.1037/t30111-000

Herold, D. M., Fedor, D. B., Caldwell, S., \& Liu, Y. (2008). The effects of transformational and change leadership on employees' commitment to a change: A multilevel study. Journal of applied psychology, 93(2), 346. https://doi.org/10.1037/0021-9010.93.2.346

Kuhnert, K. W. (1994). Transforming leadership: Developing people through delegation.

Kuhnert, K. W., \& Lewis, P. (1987). Transactional and transformational leadership: A constructive/developmental analysis. Academy of Management review, 12(4), 648-657. https://doi.org/10.5465/amr.1987.4306717

Meyer, J. P., Stanley, D. J., Herscovitch, L., \& Topolnytsky, L. (2002). Affective, continuance, and normative commitment to the organization: A meta-analysis of antecedents, correlates, and consequences. Journal of vocational behavior, 61(1), 20-52. https://doi.org/10.1006/jvbe.2001.1842

Möbius, E., Bochsler, P., Bzowski, M., Heirtzler, D., Kubiak, M. A., Kucharek, H., ... \& Fuselier, S. A. (2012). Interstellar gas flow parameters derived from Interstellar Boundary Explorer-Lo observations in 2009 and 2010: Analytical analysis. The Astrophysical Journal Supplement Series, 198(2), 11. https://doi.org/10.1088/0067-0049/198/2/11

Nadler, D. A., \& Tushman, M. L. (1990). Beyond the charismatic leader: Leadership and organizational change. California management review, 32(2), 77-97. https://doi.org/10.2307/41166606

Naude, M. J. (2015). The fight against counterfeit products in Zimbabwe: a case study at a South African automotive component manufacturer. Journal of Contemporary Management, 12(1), 249-267.

Preacher, K. J., \& Hayes, A. F. (2008). Asymptotic and resampling strategies for assessing and comparing indirect effects in multiple mediator models. Behavior research methods, 40(3), 879-891. https://doi.org/10.3758/BRM.40.3.879

Ringle, C. M., Wende, S., \& Will, S. (2005). SmartPLS 2.0 (M3) Beta, Hamburg 2005.

Schuster, S. C., Miller, W., Ratan, A., Tomsho, L. P., Giardine, B., Kasson, L. R., ... \& Alkan, C. (2010). Complete Khoisan and Bantu genomes from southern Africa. Nature, 463(7283), 943. https://doi.org/10.1038/nature08795

Sobel, M. E. (1982). Asymptotic confidence intervals for indirect effects in structural equation models. Sociological methodology, 13, 290-312. https://doi.org/10.2307/270723

Vinzi, V. E., Trinchera, L., \& Amato, S. (2010). PLS path modeling: from foundations to recent developments and open issues for model assessment and improvement. In Handbook of partial least squares (pp. 47-82). Springer, Berlin, Heidelberg. https://doi.org/10.1007/978-3-540-32827-8_3 